\title{
Scope of Social Work Practice for Families of Children with Down Syndrome
}

\author{
Bilal Ahmad Khan ${ }^{1, *}$, Wakar Amin Zargar ${ }^{1}$ and Shabir Ahmad Najar ${ }^{2}$ \\ ${ }^{1}$ Department of Social Work, University of Kashmir, J\&K, India \\ ${ }^{2}$ Centre of Central Asian Studies, University of Kashmir, J\&K, India
}

\begin{abstract}
Social work practice takes place at micro, mezzo, and macro levels between persons with disabilities in families and other social institutions, such as schools, health systems, and welfare systems. Drawing from multidisciplinary theoretical sources, the article brings together social work and family therapy to develop a possible social work intervention for families of children with Down syndrome. The primary purpose of these interventions is to aid clients in alleviating problems and improving their well being. Social workers must think creatively about interventions that may help the individuals, couples, families, and groups or communities they serve. This research is using the literature study method. The results confirm that numerous concerns have to be addressed faced by children with Down syndrome. Toward various issues and challenges faced by people with Down syndrome and their families, social workers have the professional responsibility to provide services and intervention to increase the children with Down syndrome's social functioning and overall well-being of parents.
\end{abstract}

Keywords: Social worker, Down syndrome, families, Intervention, Jammu and Kashmir.

\section{INTRODUCTION}

"Social work is a practice-based profession and an educational discipline that promotes social change and development, social cohesion, and people's empowerment and freedom. The principles of social justice, human rights, collective responsibility, and respect for diversity are central to social work. With the help of theories of social work, social science, humanity, and indigenous knowledge, social work keeps people and structures engaged in meeting life's challenges and improving well-being" [1]. Social work practice consists of an array of direct social work interventions with human beings, small groups, families, communities, plans, organizations, and other human service agencies [2]. Social work interventions can generally be described as scientifically established processes and patterns social workers apply to cases of individuals, groups, and communities. A clear systematic pattern of practicing social work began with the introduction of casework by Mary Richmond in 1922, which emphasizes clinical relationships with individuals. This is usually referred to as a one-on-one meeting with a client. With an understanding that the individual could be exaggerated by some other relational prototypes like the family, workplace, peers, and the community, practice with these other clientele categories led to further introduction of group work and community organization [3]. The present study shows that a child with Down syndrome in a family has a

*Address correspondence to this author at the Department of Social Work, University of Kashmir, India; E-mail: Khanbilz@gmail.com multi-dimensional impact on the whole family, which include economical, health and social, and any social work intervention which is proposed to be done with the families should be able to take into account the various systems within the social environment of the families which have a direct or indirect bearing on the coping ability of the families of children with Down syndrome.

\section{REVIEW OF LITERATURE}

The most common genetic cause of intellectual disability is Down syndrome and is prevalent in approximately 1 in 650 live births [4], relatively similar in most countries [5]. Globally, Down syndrome is present in six million people approximately [6]. John Langdon Down described various common physical and behavioural characteristics and portrayed the typical facial appearance, including straight and scanty hair, obliquely placed eyes, elasticity-deficient skin, and a long, thick and roughened tongue [7], and is associated with various health problems such as congenital heart disease, hearing loss, and endocrine disorders. Children with Down syndrome have an increased risk of catching an infection and are at higher risk of dying from an infectious disease than those who do not have Down syndrome [8]. The moment that parents are first informed about their child's condition is an emotional and stressful event [9]. When reality happens to be unquestionable, thoughts of blame, fear of others' reactions, and uncertainty regarding the future arise. Trapped between powerful and conflicting feelings, parents experience a stressful time in which coping depends on support from each other, extended families, friends, support groups, and skilled 
professionals [10]. Since children with DS often need constant supervision, parent-child interactive stress is a typical challenge caring for children with DS. Children's family management with DS can be more effective with resilient coping and the social support of people from other networks [11]. Parents of children with disabilities specify that they had obtained new roles, such as advocate, teacher, writer, parent-group leader, conference speaker, and member of advisory councils for schools, hospitals, and agencies representing individuals with disabilities [12]

\section{METHOD}

The literature was collected from many sources such as websites, international and national organizations, public and private organizations' published reports, provision and strategies, e-books, journals, articles, and books. It is a social science research method that refers to the analysis of documents that contain information about the phenomenon one wishes to study. A number of computer and electronic sources were used to identify studies relevant to the research questions. These included Willey Online Library, PubMed, Google Search, Google Scholars, Government websites, International and National organization's website. This article is using literature and documentation study, in the form of books, papers, and other scientific writing products, and also study of various documents connecting with the role of social workers for children with Down syndrome and their families [13].

\section{DISCUSSION}

The responsibilities of parents to children with special needs require considerable time. These responsibilities can be physically demanding for parents; they can alter family and social relationships and can affect the employment of natural carers. These additional impacts, the natural caregivers of children with the DS, may be more exposed to depression, physical health problems, and a decline in life quality. In terms of working with children with down syndrome, social workers take on the role of assisting the children with down syndrome to obtain social support and enable them to access the resources and potential to fulfill their needs. This, of course, acquires the social worker to work together with the family of the children with Down syndrome. The social worker can help the family of children with Down syndrome in addressing the problems they face by conducting their roles as social workers.

\section{Social Work Intervention Techniques for Families of Children with Down Syndrome}

Social work practice in this field spans a number of approaches and, depending on the role, can include [14].

\section{Assessment}

Assessment in most social work settings is an integral part of good social work practice. It usually provides the first opportunity for social workers and the client and family to spend a period of focused time together exchanging information and looking to the future. It will be difficult to separate assessment from the overall intervention in many social work settings because some early intervention will start in the assessment meetings. For instance, concrete needs that become apparent during these first meetings may be able to be addressed, and guidance may be given over legal and procedural issues the family may be facing. The assessment may be restricted to one or two meetings given the social work setting, but it may also be a flexible process where the entire family or only certain members are involved at different points in the assessment process. Once an intervention has commenced, future assessments may well take place as new issues emerge, and the social worker and family pause to consider what has been achieved and to indicate any new directions for the work [15]. Effective assessments enable the social worker to create a sound foundation on which the intervention can be based. Historically, the nature and success of these assessments have often depended on the availability of resources, services, and support mechanisms and on the willingness of social workers to be creative in their advocacy for clients [16]. Dealing with uncertainty is the cornerstone of genetics work in social work practice. The benefits and risks of testing are not always obvious. Helping individuals understand the limits of current knowledge and providing support when dealing with uncertainty is an important aspect of quality care and treatment. Social workers, who are often involved with clients on a long-term basis, play an instrumental role in helping individuals and families by making the necessary emotional and social adjustments to the diagnosis of a genetic disease, understand the ramifications of the diagnosis, cope with the accompanying concerns, and find appropriate services [17].

\section{The Micro-Level}

The key phases to be addressed in working directly with families at the micro level include: engaging with 
the family and forming a helping partnership, identifying possible solutions, and planning for positive change.

\section{Engaging with the Family and Forming a Helping Partnership}

This phase of the assessment process provides a foundation for subsequent phases, and the success of these will depend on how well this first phase can be achieved. When entering the world of a family, the social worker must take the time to understand the broader influences that may determine how families live their lives [16]. Families are likely to have difficulty identifying their competencies and abilities when they are immersed in challenging times.

During the assessment, the social worker's fundamental role is to help families tell their stories so that they can identify the positive facets of their experience and shed light on it to create a vision for the future. Issues in the wider environment (e.g., meeting basic needs such as income and shelter) may have to be addressed alongside other family issues. The highrisk population served by most social workers is particularly vulnerable to stress and further deterioration in family functioning [18]. Families having children with Down syndrome are at a far risk of experiencing stress than families of normal children. The grief, guilt, stigma, anger, medical care and expenses, and the likely burden of constant care are stressors that often bring crises in the family functioning. As improvements in services and treatments present, people with Down syndrome and their families with new situations and new information needs. The social worker may provide the important links which can aid families in finding support services will plan effective communication, and to design information systems to meet those needs.

\section{The Mezzo Level}

This work is often based on community organizations that have a mandate to work alongside families to improve community environments and develop more effective organizational responses to the needs of families. Many of the factors present in the direct assessment work with families are also evident at the mezzo level. For example, the close connection between theory and practice and the way one informs the other is often recognized in work at the mezzo level, as is the foregrounding of local knowledge and the harnessing of the experiences of communities and their past history in resolving issues. Context is also important; and typically, this involves social workers recognizing that families live their everyday lives within particular contexts. These will influence how they can exercise agency over the matters that impact family life. Social workers must also acknowledge the connections between the local and the global and the way in which global issues impact daily lives within neighborhoods and other communities of interest. The key theoretical approaches informing this work have historically been based on critical approaches those that focus on empowerment and structural change [15].

\section{The Macro-Level}

Work at the macro level will connect closely to that done at the mezzo level (e.g., advocacy typically arises at the mezzo level but often targets macro-level decision-makers). However, a key role at the macro level involves work in policy analysis and development as well as research and evaluation carried out in a number of key areas in federal, state, regional, and community organizations. For many social workers, this may become the focus of their work, and they may move out of direct practice to engage in these roles. Here, the knowledge they have developed in working directly with families and within communities enables them to critically evaluate the impact of policy development and implementation. Other social workers will remain in direct practice but will be aware that decisions at the macro level will have implications for practice and will determine how family services are to be resourced and delivered. These social workers may take on roles at the macro level within their direct delivery roles. This may involve activities such as advocacy for or against policy and practice developments, including submission writing and meetings with key stakeholders [15]. Work at the macro level begins with a perspective that acknowledges that what is happening in the daily lives of families is strongly influenced by wider forces [16]. This work often draws on social justice perspectives [19] that seek to address the family's needs within a framework that incorporates an understanding of the factors that may prevent families from participation and from finding ways to address their immediate concerns. The work at the macro level will be informed by work at other levels. For example, organizations can have a key role in documenting the impact of policy on service provision and delivery, and this evidence can demonstrate both positive and negative outcomes of these policies. This work at the macro-level helps families see that their issues may not be caused by their actions and relationships but may be connected to wider factors [15]. 


\section{Counseling and Therapeutic Approaches}

\section{Facilitating Communication}

A social worker often starts by inspiring family members to talk. Sometimes, families have barely talked to each other for months during counseling.

The social worker works as an unbiased third party, and serving family members share their fears, anxieties, or frustrations with non-confrontation. She/he frequently inquires that assist families in exposing the root causes of their worries. For example, if a child misbehaves, it is not because he or she disrespects his or her parents, but because he or she is upset by the stress of their parents' marriage. For example, if a child is misbehaving, it may not be because he disrespects his parents, but rather because he's troubled by tension in his parents' marriage. A social worker would help him articulate these thoughts so the entire family could discuss and understand them [20].

Social workers can help families of children diagnosed with Down syndrome in a number of ways. They often offer emotional support to parents who try to cope with the news about a diagnosis. Social workers can help parents identify strategies for dealing with stress and their emotions. They can answer questions and provide diagnostic information. They can inform parents about the services and resources available for their children with Down syndrome. Time and again, social workers help parents understand the treatment needs and the types of specialists they need to deal with their children's medical condition, learning disabilities, and developmental delays. Social workers are also responsible for sharing information on how parents can get help with practical needs, such as financial distress that may result from additional medical care that may be needed by a child with Down syndrome. A social worker can help by assisting families or by connecting parents with available agencies and organizations.

\section{Intervention}

Social workers who appreciate the hardships faced by their service users can help them understand their feelings of pain and suffering, and help them identify their relationships with systemic barriers that are based on oppressive professional expectations that form "good parenting" [21]. Facilitating the family's communication about the testing and its implications is essential. Support for family members undergoing testing and adjusting to the information is important.
Social work will often try to soothe the family unit, including addressing individual member's issues, so that counseling will be more efficient. The main purpose of counseling a parent with a child with Down syndrome is to set realistic goals for the child and ensure an acceptable place in the family. The dynamic environment gives the child the best opportunity to reach their full potential. Family-centered counseling for individuals and families helps the identified patient consider the broader impact on his or her family. Social workers have the training to help families address this complex situation, which has implications across the family system. Social work's role in genetics came from the evolution of genetic counseling as a unique profession. The trans-disciplinary team in these genetic clinics includes medical geneticists, genetic counselors, nurses, and sometimes social workers. Specialized genetic clinics provide several types of services: Genetic counseling - Clarification and confirmation of genetic diagnoses, especially for rare disorders - Risk assessment - Carrier testing services - Predictive testing - Predisposition testing - Prenatal diagnoses • Consultation with primary providers for treatment Follow-up of development and other medical treatment needs throughout the life span [17]. After determining prenatal screening, doctors went to great lengths to tell their parents how they were getting their child with Down syndrome. Many mothers feel unaware of Down syndrome and rely on a doctor to run the information. However, many physicians know the medical information about Down syndrome but did not have experience with people with Down syndrome, which often leaves uneven information for the mother [22]. The physician is by no means the only professional engaged in this kind of counseling. Some physicians may not even do a very good job of telling parents what has to be told." Although the physician will be looked on as the primary source of relevant information, he or she should consider using the services of a well-trained social worker in these cases. Parents readily accept a team approach of physicians and social workers. The hospital nurses should also be supportive and should display sensitivity by using appropriate words, supplying factual information if needed, and facilitating contact between parents and children [23]. The first counseling session might well be short-term without going into details; generally, the worried parents can embrace only a few of the suggestions presented to them. An intense emotional interchange occurs, disrupting logical thought processes and allowing the only limited transfer of actual knowledge. Hope, denial, and other defense mechanisms often help the parents 
sustain themselves emotionally during the subsequent adjustment period, so the physician's remarks should be timed to coincide with increasing parental adaptive capacity. Follow-up sessions are necessary for a review of basic considerations and communication of details. Then, parents can better articulate feelings and formulate questions. The physician's extra time talking about various expressed concerns and issues will make the parents aware of his sincere interest in helping them and their children. The parents should be told the meaning of the term Down's syndrome and why its use is preferred to the offending misnomers "mongoloid," "mongolism," and "Mongolian idiot." "Retardation" also needs to be explained, as it is often interpreted as meaning helplessness. Physical characteristics of Down's syndrome and their relative frequency should be pointed out, as well as the implications of congenital anomalies [23].

\section{Capacity Building}

Involve, educate, advise and coordinate local community groups, networks, businesses, and local government to build a more welcoming and inclusive community for people with disabilities by removing barriers to physical and social access and membership [14]. The effects that a disability has on an individual are greatly influenced by the community's attitudes and opportunities that he or she is living in. For the past decade, most children with Down syndrome have suffered from social and educational disadvantages. Children with Down syndrome were not welcomed in the same clubs, playgroups, and social activities in which children of their age group participated. They only mingled with children with similar or more severe disabilities in isolated settings. They were deprived of friendships with other people of their age who were not having any disability. They were not learning and growing within the world of children in their community. Imagine how social isolation and exclusion from school would affect children's development without a disability and then consider its probable effect on the development of children with Down syndrome.

Work within normal services to raise awareness, understanding, and knowledge about the problems of persons with disabilities and their families to provide appropriate and effective services and support.

Building capacity of individuals or families to navigate health and welfare systems or access information [14]. Those with most influence on the development of babies are their families. The quality of care, love and attention provided at home creates the first learning and growing opportunities for all children. Babies and children with Down syndrome, like all other children, benefit from loving and secure home environments, where they are played with, talked to and valued as family members. All children grow up in families that encourage their children to be independent and behave in socially acceptable ways from an early age. All children thrive in families that praise and value all their children's' achievements and where all family members care for and support one another. In the past, families were advised to put their babies with Down syndrome into institutions, and this still happens in some countries. However, the families of individuals with Down syndrome have been the main force for change in most countries, supporting one another and fighting for a change in attitudes, appropriate services, and education for their children and young people [24].

Social workers are increasingly emphasizing their role in preventing social ills. Often, though, they do not have access to groups of people involved in the common crisis. Children with birth defects are usually not brought to the attention of social workers unless the family shows an adjustment problem or a specific social plan is needed. The chances of social workers meeting with groups of families with common stress draw attention to common needs that professionals do not meet. The experience of such a group can be helpful for professionals as it focuses on important topics and the needs of groups of people rather than dealing with individual pressures and adaptation of individuals. Two developments that came forward from this group work were an educational program for professionals on the needs of parents who had given birth to a child with Down's syndrome and a program of information and support for the siblings of such children [25].

\section{Case Management and Service Coordination}

Case management can be defined as a social service delivery approach that seeks to ensure that clients with multiple and complex issues and disabilities receive their services in a timely and appropriate manner. Case managers, who may be social workers, nurses, psychologists, and members of other healthcare professions, may work independently or as members of coordinated teams. The objectives of service delivery in case management include permanence of care, convenience, accountability, and efficiency. The case manager is responsible for service 
coordination and helping the client hold elements of the service system accountable for adequate service delivery [15]. The worker must have the ability to work in a multi-dimensional medical environment and have a good foundation in psychiatric concepts. During this process, the social worker is more than just the coordinator of a treatment plan, but rather acts as the chief teacher and parent to the patient, guiding him gently at his own pace into realistic paths and toward achievable goals [26].

\section{Micro-Level}

Because the practice of case management involves many services provided by many agency practitioners in distinctive community service systems, it is difficult to confidently generalize findings from one program to another program. For this reason, it is important to acknowledge the role of the individual case manager in helping programs meet overall objectives and helping clients to meet their goals. In short, people deliver services, not programs. It is important to utilize highly skilled case managers who will have access to ongoing supervision, training, and continuing education opportunities at the micro-level. Case managers also need to be given the flexibility to titrate their activities to address the particular characteristics of their clients and community systems [18]. Parents/caregivers have to take their children to undergo all the aforementioned procedures owing to the different types of assessment. However, in some cases, the most effective intervention is to refer children directly for specialist intervention without the gate-keeping of other levels. One example is children with Down syndrome, who, under the existing system, must undergo all the aforementioned assessment or gate-keeping procedures before they can obtain relevant intervention. This procedure may not be necessary, provided that we can recognize the physical appearance of children with Down syndrome. Meanwhile, schools implement continuous assessments by teachers, educational psychologists, and, eventually, external specialists. The different levels of assessment preclude efficient and effective assessment and intervention for children in need [27]. An implicit hierarchy exists from assessment (doctors and / or psychologists) to paramedical intervention (occupational and speech therapists) and final to social work intervention or education (social workers and teachers). Such implicit hierarchy suggests that paramedical intervention is more important than social work intervention or education. From a rehabilitation point of view, all interventions are equally important for a person's holistic development. However, parents/caregivers attempt to look for less stigmatized paramedical intervention (i.e., the child is "sick") rather than social work or educational intervention (i.e., "the child has specialized needs"). Case management is very often fragmented. Family intervention is neglected in favour of individual treatment for children with developmental issues. Familial support is not well addressed, and there is no widely adopted framework for holistic intervention for both the children and their families [27].

\section{Mezzo Level}

Agency administrators need to be aware that case management practice is often stressful, frustrating, and conflict riddled. Administrators need to be able to provide their case managers with an agency atmosphere that is supportive of their work, concretely values their work (via salaries, benefits, recognition, advancement opportunities), and actively deals with the possibility of worker burnout. While the benefits to clients and public budgets are clear, the short half-life of case managers is also well known. Administrators can help to support the work of case managers by offering competitive compensation packages, agreeable working conditions, adequate agency material supports, and close access to referral providers such as agency physicians, reasonable caseload sizes, and opportunities for professional advancement [15].

\section{Macro Level}

All policymakers hope that their case management programs are effective across a range of client goals that include quality of life and that those programs are cost-effective in comparison to treatment alternatives. Given the various ways in which case management programs "play out" in different service systems, it is still hard to understand what works for what clients under what circumstances. Further, when a program is implemented, it cannot be assumed that it will unfold precisely the manner that the policymakers have intended. Policymakers should ensure that case management programs are available in all localities for persons with mental illness, but they should be hesitant about promoting "exact" replications from one service setting to another. Further, the interests of cost containment and quality of life may best be achieved if policymakers allow for competitive markets to develop along the lines of privatization as well. It seems that this can be best achieved if the dollars follow the client 
rather than being provided to various providers in the purchase of service agreements [15].

\section{$>$}

Service brokerage

Coordinating support

Collaborating with multidisciplinary teams

Referrals to other services

Accessing resources

Assistance with housing

Assistance with advanced care planning, including obtaining guardianship and/or administration orders if necessary to support decision making

Parents or caregivers of children with Down syndrome can access many medical or developmental facilities. The coordination of these services depends on communication between primary care providers and specialist care services, as well as access to services and support. Despite research studies, advocacy, and the media's focus on Down syndrome, the families of children with Down syndrome do not receive as much public attention as the families of children with other health issues. The families should be provided with appropriate information and referrals to services before or shortly after the child's birth in a reliable, timely, and family-centered manner. Parents require the latest general information about their children's diagnosis and specific information about health status, treatment, and services available. However, families of children with Down syndrome face challenges finding and accessing care, despite significant improvements in awareness, specialist care, education, and family support. The multidisciplinary team's efforts assist them on an ongoing basis, including nurses, physiotherapists, doctors, and social workers. They all emphasized that the support group itself helps them deal effectively with the challenges they encounter in their lives and found that the self-help group is a valuable and appropriate source of practical and emotional support for families affected by a genetic condition [28].

\section{Advocacy}

A useful starting point for exploring the meaning of advocacy in social work is the concept of "roles of social workers." The most frequently mentioned roles include enabler, broker, mediator, advocate, resource person, gatekeeper, educator, and trainer, which overlap to various degrees. This conceptual instrument, the roles of social workers, is built on various combinations of actions, relationships, and systems in the context of social work practice. For instance, the advocate role of the social worker involves actions of advocating or doing advocacy. In the case of helping a client to obtain a service, once denied, the social worker acts on behalf of clients (involving relationships) to negotiate (involving actions) with the relevant service provider (involving service delivery systems) to ensure that their human rights are protected [15]. The process of advocacy is tremendously supportive to social workers as they put effort into discovering educational services. For instance, a child with Down syndrome is an exceptional applicant for early intervention services. It is essential to recognize these children and their families and to refer them for early intervention because "sufficient proof exists that the provision of these early intervention services can surely change the course of development for these children. Furthermore, the general need is for a referral to sources of possible monetary help [29].

\section{Planning}

Facilitate planning by providing information about resources to maximize choice and opportunities for the person to achieve the life he or she wants [14].

User-led advocacy movements among persons with a disability, survivors of mental illness, and other groups are gathering momentum in bringing about changes in society. Many small user groups are actively participating in advocacy and forming themselves into communal or district coalitions, national alliances, and ultimately international platforms for social and policy changes. Social workers can serve as support and coaches for users to form themselves into user-led advocacy groups or organizations. At the same time, social work professional organizations or groups can form alliances with advocacy users' groups to promote desirable social reform in social systems, policies, policy implementations, and priorities in resource allocation. It is crucial for social workers to be equipped with knowledge and skills in staying in the background while helping our clients use advocacy for change. Advocacy has always been part of professional social work practice, including social workers' contribution and participation in networking, capacity building, resource mobilization, advocacy of rights without neglecting responsibilities, policy change, and attitude change. However, with increasing professionalization and privatization of services, social workers view themselves more and more as 
gatekeepers to protect clients from unjust service delivery systems. There are intense debates in the profession regarding a fundamental reexamination of social workers' role in advocacy and system change [15]. Social workers are historically linked to orchestrating changes in people's lives through collective action, advocacy for effective social policy, empowerment through community development, fostering communication through family interventions, and individual casework. Schneider and Lester (2001, pp. 58-64) identified the key dimensions of advocacy as (a) pleading or speaking on behalf of others, (b) representing another, (c) taking action, (d) promoting change, (e) accessing rights and benefits, (f) serving as a partisan, (g) demonstrating influence and political skills, (h) securing social justice, (i) empowering clients, (j) identifying with the client, and ( $k$ ) establishing a legal basis. They described social work advocacy as "the exclusive and mutual representation of a client(s) or a cause in a forum, attempting to systematically influence decision making in an unjust or unresponsive system(s)" (p. 65). Fueled by the passion for serving humanity, social workers often launch programs to advocate for and empower disadvantaged and underprivileged populations, such as single parents; and persons with disabilities, physical, or mental illnesses [15].

\section{Mediation and Conflict Resolution}

Helping people with disabilities and their families in the resolution of conflicts that arise among themselves or with others

Most mediation/conflict resolution models fit well with social work's core values of the dignity and worth of each person, the importance of human relationships, and the pursuit of social justice [30]. Like other helping professions, social workers have an advantage in working with mediation/conflict resolution processes as they have a working knowledge of human development and interpersonal relationships compared to the legal profession. As with other helping professions, social workers are trained to demonstrate empathy with a wide range of human conditions. This would suggest that social workers have the initial skill set to be mediators, and as such, should have specialized training in the area of mediation/conflict resolution. Social workers who are trained in these skills could have greater success managing conflict in areas such as families, aging, mental health, child/parent relationships, adoption, community, education, workplace, criminal justice, social policy, intercultural issues, divorce, post-divorce parenting, parent and child relationships, healthcare, and mental health. In addition, conflict resolution skills can be adapted to disability issues, workplace harassment, criminal justice, and social policy [30].

\section{CONCLUSION}

The professional social workers working in the field of developmental disabilities have a lot to contribute to both government and non-government organizations and the emerging private sector. Social workers who focus on self-determination and holistic analysis make unique contributions by providing appropriate and targeted services to meet people's life needs with disabilities, their families, and communities. If parenting can significantly impact children's development, in that case, one likely possibility is that children's rate of developmental growth can be enhanced by primarily focusing intervention efforts on increasing the effectiveness of parents at engaging in responsive interactions with their children. This multi-focused approach takes into account comprehension of the functioning of humans and behaviour, and how socioeconomic, legal and cultural factors interact and impact to produce the dishonor, prejudice, marginalization, and social segregation experienced by many individuals with a disability and their families. Social workers develop evidence-informed assessments, planning, and interventions within a client empowerment framework. Social work interventions consider the impact of health, psychosocial, or other needs of the individual and their support systems. Social workers regularly join multidisciplinary teams, especially when interventions are part of complex social, psychological, familial, and institutional dynamics. In this regard, social workers can share the decision-making capabilities of other professionals and the multidisciplinary team. Above all, social workers respect the dominance of individual rights and work for people with disabilities to improve their lives.

\section{REFERENCES}

[1] International Federation of Social Workers - IFSW [internet] Global Definition of the Social Work Profession. 2019 April 13. Retrieved from https://anzasw.nz/international-federationof-social-workers-ifsw/

[2] Chukwu N, Chukwu NN, Nwadike N. Methods of Social Practice. In Okoye U, Chukwu N, Agwu P, (Eds.). Social work in Nigeria: Book of readings. Nsukka: University of Nigeria Press Ltd. 2017; pp. 44-59.

[3] Austin MJ, Coombs M, Barr B. Community-Centered Clinical Practice. Journal of Community Practice 2005; 13(4): 9-30. https://doi.org/10.1300/J125v13n04_02 
[4] Bittles AH, Bower C, Hussain R, Glasson EJ. The four ages of Down syndrome. Eur J Public Health 2007; 17: 221-225. https://doi.org/10.1093/eurpub/ckl103

[5] Collins VR, Muggli EE, Riley M, Palma S, Halliday JL. Is Down syndrome a disappearing birth defect? J Pediatr 2008; 152(1): 20-4, 24.e1.

https://doi.org/10.1016/j.jpeds.2007.07.045

[6] Ballard C, Mobley WC, Hardy J, Williams G, Corbett A. Dementia in Down's syndrome. Lancet Neurol 2016; 15: 622636.

\section{https://doi.org/10.1016/S1474-4422(16)00063-6}

[7] Dekker AD. Down and Alzheimer: Behavioural biomarkers of a forced marriage [Groningen]: Rijksuniversiteit Groningen 2017.

[8] Van Riper M, Cohen WI. Caring for children with Down syndrome and their families. Journal of Pediatric Health Care 2001; 15(3): 123-131.

https://doi.org/10.1067/mph.2001.110627

[9] Marchal JP. Growing up with Down syndrome: The developing child and its parents 2017.

[10] Huiracocha L, Almeida C, Huiracocha K, Arteaga J, Arteaga A, Blume S. Parenting children with Down syndrome: Societal influences. Journal of Child Health Care 2017; 21(4): 488-497.

https://doi.org/10.1177/1367493517727131

[11] Onyedibe MCC, Ugwu LI, Mefoh PC, Onuiri C. Parents of children with Down Syndrome: Do resilience and social support matter to their experience of carer stress? Journal of Psychology in Africa 2018; 28(2): 94-99. https://doi.org/10.1080/14330237.2018.1455308

[12] Van Riper M. Families of Children with Down Syndrome: Responding to "A Change in Plans" with Resilience. Journal of Pediatric Nursing 2007; 22(2): 116-128. https://doi.org/10.1016/j.pedn.2006.07.004

[13] Md. Mahmudul Hasan, Mohammad Kamrujjaman. Comparative Study of Supporting Services for Children with Down's syndrome and their Families: Perspective of United Kingdom and Bangladesh. Current Trends in Clinical and Medical Sciences 2019; 1(1): CTCMS.MS.ID.000501. https://doi.org/10.33552/CTCMS.2019.01.000501

[14] Australian Association of social workers [internet]. Scope of Social Work Practice Social Work in Disability. 2016. Retrieved from https://www.aasw.asn.au/document/item/ 8665

[15] Sowers KM, Dulmus CN, Colby IC. Comprehensive handbook of social work and social welfare. Hoboken, NJ: Wiley 2008. https://doi.org/10.1002/9780470373705

[16] Munford R, Sanders J. Supporting Families. Palmerston North, New Zealand: Dunmore Press 1999.
[17] Browne TA, Gehlert S. Handbook of health social work. Hoboken, NJ: Wiley 2006.

[18] Thyer BA, Dulmus CN, Sowers KM. Developing evidencebased generalist practice skills. Hoboken, NJ: Wiley 2013.

[19] Finn J, Jacobson M. Just practice: Steps toward a new social work paradigm. J Soc Work Educ 2003; 39: 57-78. https://doi.org/10.1080/10437797.2003.10779119

[20] Williams E. Role of Social Worker in Family Counseling. [2016, November 09] Retrieved from https://work.chron.com/ role-social-worker-family-counseling-13712.html

[21] Woodcock J, Tregaskis, C. Understanding Structural and Communication Barriers to Ordinary Family Life for Families with Disabled Children: A Combined Social Work and Social Model of Disability Analysis. British Journal of Social Work. 2008; 38(1): 55-71. https://doi.org/10.1093/bjsw/bcl065

[22] Williams C, Alderson P, Farsides B. What constitutes 'balanced information in the practitioners' portrayals of Down's syndrome? Midwifery 2002; 18(3): 230-237. https://doi.org/10.1054/midw.2002.0316

[23] Pueschel S, and Murphy A. Counseling parents of infants with Down's syndrome. Postgraduate Medicine 1975; 58(7): 90-95.

https://doi.org/10.1080/00325481.1975.11714224

[24] Buckley S. Living with Down syndrome. The Down syndrome educational trust, Portsmouth. UK: Down syndrome Education International 2000

[25] Murphy A, Pueschel SM, Schneider J. Group Work with Parents of Children with Down's syndrome. Social Casework 1973; 54(2): 114-119. https://doi.org/10.1177/104438947305400206

[26] Shotland L. Social work approach to the chronically handicapped and their families. Social Work 1964; 9: 68-75.

[27] Rubin IL, Merrick J, Greydanus DE, Patel DR. Health care for people with intellectual and developmental disabilities across the lifespan. Switzerland: Springer 2016.

https://doi.org/10.1007/978-3-319-18096-0

[28] Mathebane SM. The lived experiences of Black African mothers following the birth of a child with down syndrome: Implications for indigenisation of social work. Social Work 2016; 52(2): 167-187. https://doi.org/10.15270/52-2-499

[29] Cole BS, Pearl LF, Welsch MJ. Education of social workers for intervention with families of children with special needs. Child \& Adolescent Social Work Journal 1986; (4): 327-338. https://doi.org/10.1007/BF00755225

[30] Kelly DR. Social work mediation/conflict resolution: The benefits, challenges, and practitioner improvements associated with the use of mediation/conflict resolution in social work practice (Unpublished doctoral dissertation). 2014.

\section{DOI: https://doi.org/10.6000/2292-2598.2020.08.04.17}

(C) 2020 Khan et al.; Licensee Lifescience Global.

This is an open access article licensed under the terms of the Creative Commons Attribution Non-Commercial License (http://creativecommons.org/licenses/by-nc/3.0/) which permits unrestricted, non-commercial use, distribution and reproduction in any medium, provided the work is properly cited. 